\title{
Potential Changes in Hydrologic Hazards under Global Climate Change
}

\author{
Koji Dairaku \\ National Research Institute for Earth Science and Disaster Prevention, \\ Japan
}

\section{Introduction}

The water cycle is vital to life and ecosystems. The water cycle regulating climate stability and variability has complex interactions within the climate system and plays a basic role in it, therefore changes in the water cycle have arguably the most substantial impact on climate change.

Water-related natural disasters have increased in the last decade due to population growth, land use and land cover change such as urbanization or cultivation, and climate change. Historically, stable climatic conditions have been assumed for water resource management, planning, and civil engineering design. Although some predictions remain uncertain, the Intergovernmental Panel on Climate Change (IPCC) concluded that precipitation in high latitudes is increasing as decreases occur in most subtropical land regions. Extremes such as hot extremes, heat waves, and heavy precipitation will continue to become more frequent and tropical cyclones -- typhoons and hurricanes -- will become more intense [1]. Changes in the water cycle and extreme threats to life and ecosystems, such as droughts, floods, and soil erosion, constitute a basic global-warming concern. Water resource planners must increasingly quantify the risk of extremes [2].

Global climate changes may lead to changes in rainfall events by enhancing atmospheric moisture content [3]. Saturation vapor pressure governed by the Clausius-Clapeyron equation is observed and projected to increase by about $7 \% \mathrm{~K}^{-1}[4,5]$. A large portion of water vapor exists in the lower troposphere. Therefore column-integrated water vapor is primarily weighted by the lower troposphere. On the other hand, water vapor in the upper troposphere is relatively low and not directly constrained by the thermodynamic arguments. Soden et al. [6] reported a distinct radiative signature of upper tropospheric moistening by satellite measurements from 1982 to 2004. It also supports the robustness of the projected increase in column-integrated water vapor with global warming. Moisture is supplied to moderate or heavy precipitation mainly by transport, not from local evaporation. Three to five times the radius of the precipitating region expands to collect moisture over the area [4], therefore convective rainfall drawing in increased moisture from the surrounding atmosphere is expected to increase at the rate of water vapor, thus increasing the risk of extreme events such as flooding and heavy snowfall.

Emanuel [7] reported that the longevity and intensity of tropical cyclones have increased over the last 30 years. Webster et al. [8] concluded that the number of recent tropical cyclones of categories 4 and 5 in the last 35 years has increased. Due to their rare occurrence 
and the large natural variability of tropical storms, however, it is difficult to attribute change to global warning signals of climate change. A relatively high resolution (T106) atmospheric general circulation model (AGCM) projected the increase in precipitation of tropical cyclones in response to increased atmospheric moisture content despite decreased their frequency and intensity [9]. A higher resolution AGCM (20km-mesh) suggests that decrease of frequency in tropical cyclone (but increase in the North Atlantic), increase of the number of intense tropical cyclones, and increase in maximum surface wind speed of the most intense tropical cyclone [10]. Because they fail to provide compelling evidence, these reports and research are inconclusive. The events recently experienced are high-impact, amply evident of the urgency we face in learning to adapt to climate changes and cope with climate variability.

Prospects are increasing for changes in extremes such as droughts and floods profoundly impacting on society and the economy. These prospects are only now being adequately faced or addressed after release of the fourth assessment report of the IPCC [1] in studies on the impacts of climate change. Changes in extremes affect agriculture, hydrology, water resources, and the economies of many Asian countries where billions of people live. To adapt to climate changes in the face of drought, flood, and soil erosion, which frequently seriously threaten life and ecosystems, predictions and risk assessments in this area are required more frequently by policymakers.

Hydrologic predictions accounting for global climate changes mainly use GCMs $[3,11,12$, 13, 14]. Despite numerous studies, the regional responses of hydrologic changes -atmosphere-ocean-land interactions, precipitation, and extreme events such as droughts and floods -- resulting from climate change remain unclear and involve many uncertain factors, e.g., the large amplitude of natural variability and anthropogenic influences such as black carbon, deforestation, and irrigation. Coarse spatial resolutions with grid spacing of approximately $300 \mathrm{~km}$ and uncertain physical processes limit the representation of terrestrial water/energy interaction and the variability and extremes in such systems as the Asian monsoon. Only very restricted regional-scale estimates are available to planners. Relatively high-resolution GCMs are now being developed and ensemble projections producing useful probability distributions can be provided to risk assessment models by improved computer capabilities.

We address two recent attempts of hydrologic projection under global climate change - (i) projected extreme events in the Asian summer monsoon with relatively high-resolution ensemble simulations and (ii) a case study of flood risk assessment in a watershed in Japan using multi-model ensemble projections based on atmosphere-ocean coupling general circulation models (AOGCMs) contributed to IPCC AR4.

\section{Extreme events in the Asian summer monsoon with high-resolution GCM}

The response of the Asian summer monsoon to global warming is of critical concern to Asia's large population. Despite numerous studies, however, the response remains unclear. Past studies have investigated factors that control the Asian summer monsoon, showing greater South Asian summer monsoon precipitation and interannual variability caused by enhanced land-sea thermal contrast [15] or by warmer ocean sea surface temperatures (SSTs) that provide more moisture [16] during global warming. Past studies have also shown a northward shift in lower tropospheric monsoon circulation and increased summer monsoon rainfall due to increased water vapor in the warmer atmosphere [17, 18, 19, 20, 21]. 
May [22] suggested weakened monsoon circulation and greater precipitation. Mitchell and Johns [23] theorized that additional forcing by aerosols could weaken monsoon circulation. Low-resolution climate models with grid spacing of approximately $300 \mathrm{~km}$ are particularly limited in forecasting possible changes in variability and extremes of daily rainfall during the Asian summer monsoon, and few modeling studies have been conducted [17, 24]. Many researchers have argued that increases in mean South Asian summer monsoon rainfall arise primarily from enhanced atmospheric moisture. Increases in water vapor can explain only part of the change, however, especially changes in daily precipitation [25, 26]. Emori and Brown [25] showed dynamic enhancement in lower latitudes mainly over the oceans and suppression over subtropics. Thermodynamic effects, however, were enhanced almost globally except for subtropical ocean, in mean change, corresponding to the increase in atmospheric moisture content. Taking results from high-resolution ensemble simulation with the AGCM $[27,28]$ on the earth simulator, we studied daily precipitation during the Asian summer monsoon.

\subsection{Model and experiments}

We ran time-slice experiments -- a five-member ensemble for the control and a sevenmember ensemble for $2 \times \mathrm{CO}_{2}$-- using the Center for Climate System Research/National Institute for Environmental Studies/Frontier Research Center for Global Change (CCSR/NIES/FRCGC) AGCM. This model featured T106 spectral truncation in the horizontal (approximately $1.1^{\circ}$ on an equivalent grid) and 56 vertical layers.

Each ensemble member covered 20 years. Ensemble simulation enhanced the statistical reliability of changes diagnosed in precipitation, particularly extreme events. Lower boundary forcing for control runs included SST and sea-ice concentration data for 1979-1998 provided by the Hadley Centre Global Sea Ice and Sea Surface Temperature (HadISST) dataset [29]. Each ensemble member was run with different initial conditions taken from a multiyear spinup run. Additional forcing for the $2 \times \mathrm{CO}_{2}$ runs included seasonally varying SST anomalies derived from transient climate change experiments from different coupled GCMs -- CCSR, NCAR-CSM, NCAR-PCM, MPI, GFDL, CSIRO, and CCC. Output from these models was obtained from the IPCC Data Distribution Center (DDC), and additional forcing was added to control run forcing as "warming patterns." $\mathrm{CO}_{2}$ concentrations were 345 ppmv for controls and 690 ppmv for $2 \times \mathrm{CO}_{2}$ experiments.

The control ensemble showed uncertainty due to internal atmospheric variability, and results from $2 \times \mathrm{CO}_{2}$ ensembles showed uncertainties from both internal variability and projected externally forced SST change.

\subsection{Change in mean South Asian summer monsoon features}

Precipitation and typical large-scale circulation patterns, e.g., strong easterlies in the upper troposphere and strong westerlies in the lower troposphere (Fig. 1a) agreed with observations during the summer monsoon season from June to September (JJAS, not shown). A general increase in the 2-meter air temperature by 2-6 K was projected in the region during JJAS. Greater warming occurred over land areas, such as the Tibetan Plateau, than over the ocean (Fig. 1b). Figure 1c shows a northward shift in lower tropospheric wind systems and enhanced precipitation over land in South Asia -- changes that agree with those in previous studies $[17,18,19,20]$. Greater evaporation in this area enhanced the local water vapor supply (not shown). Larger moisture content in warmer air enhanced the water vapor 
flux, which increased Asian summer monsoon rainfall over land (Figs. 1c and 1d). Changes in precipitation indexes -- area-averaged rainfall near India $\left(8.5^{\circ}-30^{\circ} \mathrm{N}, 65^{\circ}-100^{\circ} \mathrm{E}\right)$ and over land only [30] -- were $3.36 \%$ and $9.93 \%$. Two dynamic indexes related to vertical zonal wind shear (U-shear) associated with Walker circulation [31] and vertical meridional wind shear (V-shear) associated with local Hadley circulation [32] could indicate projected change in the large-scale monsoon flow. Changes in U-shear were $-7.46 \%$ and in V-shear $-9.31 \%$. These changes in weakening are attributable to shifts in the mean location of convergence over India and the tropical Indian Ocean. Current geostationary indexes may not, however, be appropriate [18] if positions of circulation systems change as a result of global warming.

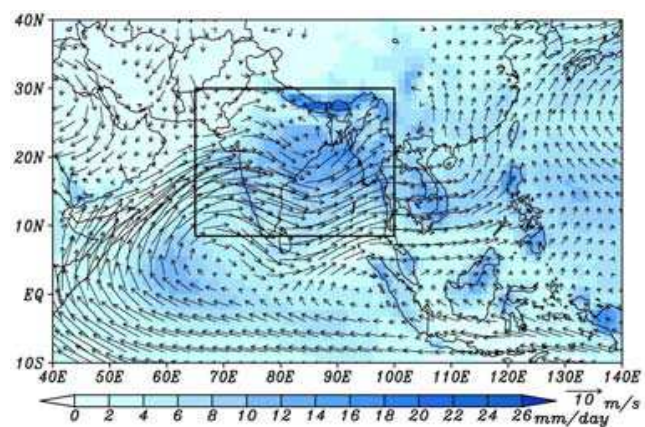

(a)

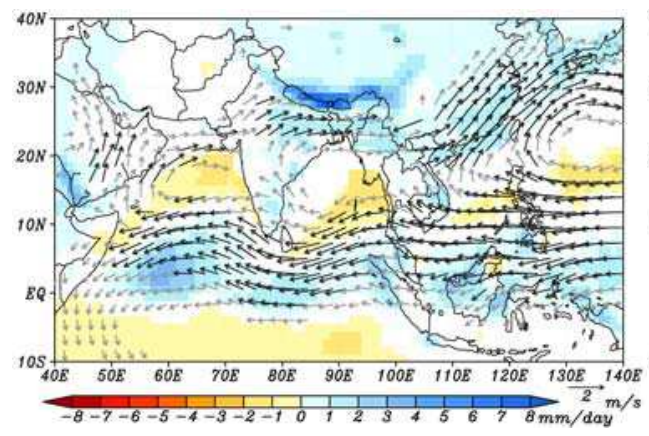

(c)

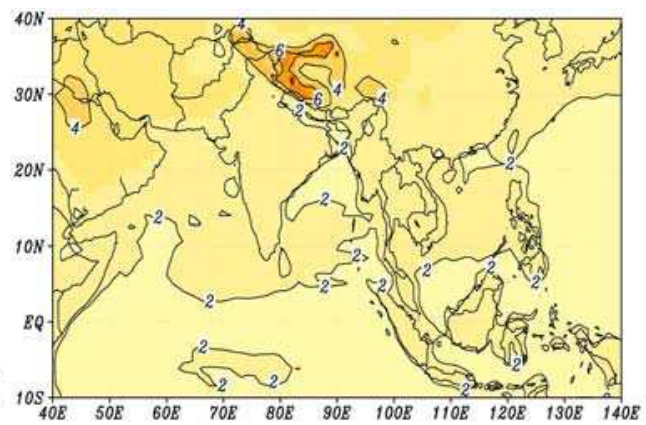

(b)

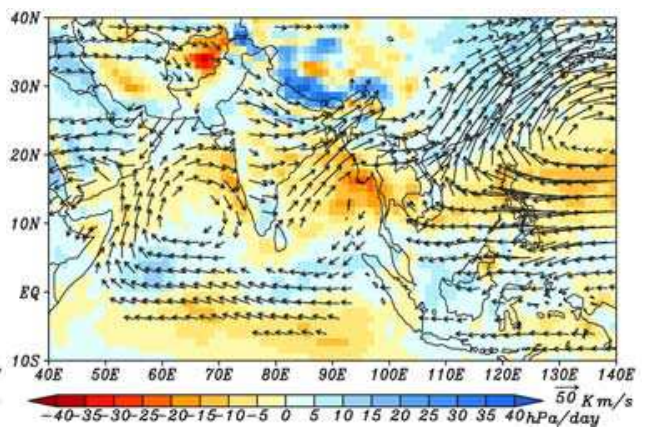

(d)

Fig. 1. (a) Simulated present mean precipitation and horizontal wind at $850 \mathrm{hPa}$ over Asia during JJAS. Projected mean changes in (b) $2 \mathrm{~m}$ air temperature, (c) precipitation and horizontal wind at $850 \mathrm{hPa}$, and (d) vertically integrated water vapor flux and upward vertical velocity at $500 \mathrm{hPa}$.

The rectangle in (a) outlines the region $\left(8.5^{\circ}-30^{\circ} \mathrm{N}, 65^{\circ}-100^{\circ} \mathrm{E}\right)$ used in Figs. 2-5. The temperature change in (b) exceeds the $99 \%$ confidence level. Shading in (c) shows precipitation changes statistically significant beyond the $95 \%$ level. Gray and black vectors in (c) show changes in wind speed exceeding 0.5 and $1.0 \mathrm{~m} / \mathrm{s}$; the reference vector is $2 \mathrm{~m} / \mathrm{s}$. Vectors in (d) show changes in water vapor flux exceeding $2.0 \times 10^{4} \mathrm{~m} / \mathrm{s}$; the reference vector in $(\mathrm{d})$ is $5.0 \times 10^{4} \mathrm{~m} / \mathrm{s}$. 


\subsection{Change in extreme precipitation}

Figure 2 shows the frequency distribution of daily precipitation over land in South Asia $\left(8.5^{\circ}-30^{\circ} \mathrm{N}, 65^{\circ}-100^{\circ} \mathrm{E}\right)$ and China $\left(20^{\circ}-40^{\circ} \mathrm{N}, 100^{\circ}-130^{\circ} \mathrm{E}\right)$ during JJAS. Simulated daily rainfall frequency in control experiments agreed relatively well with Global Precipitation Climatology Project (GPCP 1DD) data, although strong (approximately $20-30 \mathrm{~mm} /$ day) and extreme precipitation (>60 mm/day) events were overestimated. In China, simulated precipitation agrees well with observations. The limited validity of simulated extreme events in South Asia is partly due to the lack of observation because station measurements of daily precipitation are available only over limited land regions with dense population. Model validity should be refined by further improving parameterization. The intensification of extreme precipitation ( $>50 \mathrm{~mm} /$ day) occurred in $2 \times \mathrm{CO}_{2}$ experiments, and the change exceeded the uncertainty range of one ensemble standard deviation in both South Asia and China (thin dashed lines in figure).

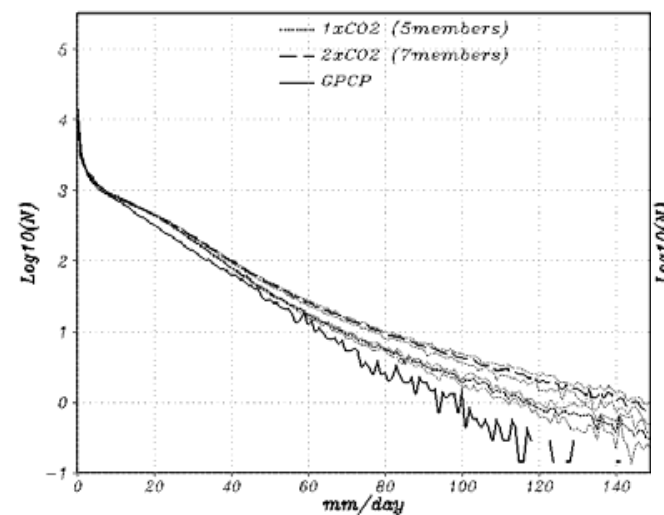

(a)

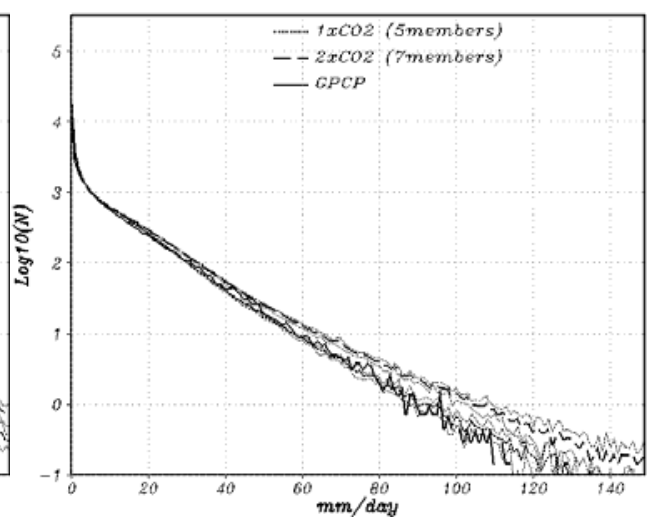

(b)

Fig. 2. Frequency distribution of daily precipitation over land of (a) South Asia $\left(8.5^{\circ}-30^{\circ} \mathrm{N}\right.$, $\left.65^{\circ}-100^{\circ} \mathrm{E}\right)$ and $(\mathrm{b})$ China $\left(20^{\circ}-40^{\circ} \mathrm{N}, 100^{\circ}-130^{\circ} \mathrm{E}\right)$ during JJAS. Solid lines show observations from the GPCP 1DD (1997-2003). The short dashed line and long dashed line denote the ensemble average from the control and $2 \times \mathrm{CO}_{2}$ experiments. Thin dashed lines show the standard deviation of each ensemble.

Projected increase in mean South Asian summer monsoon rainfall is attributable primarily to enhanced atmospheric moisture as argued in previous studies. The question remains, however, whether the increase in water vapor alone is sufficient to explain the change in monsoon precipitation. Only part of changes in daily precipitation could be explained by the increase in water vapor. An investigation of the influence of dynamic and thermodynamic changes on possible daily precipitation is thus addressed.

Figure 3 shows expected daily precipitation to daily $500 \mathrm{hPa}$ vertical velocity (dynamic regime). In contrast to the usual definition of pressure velocity, however, the positive values of $\omega$ showed ascent, and negative $\omega$ showed subsidence. The relative frequency of extreme upward motion was very small, but heavy precipitation would accompany a strong upward motion regime. A substantial enhancement of expected precipitation intensity for a given dynamic regime was noticeable and exceeded the uncertainty range of one ensemble standard deviation (thin dashed lines). Changes in extreme precipitation (17.4\%; average of 
$500-1000 \mathrm{hPa} /$ day) were largely consistent with precipitable water increases $(18.9 \%)$ in the region of South Asia. It is almost same in China. The changes were quite likely due to increases in atmospheric moisture content, i.e., thermodynamic changes.

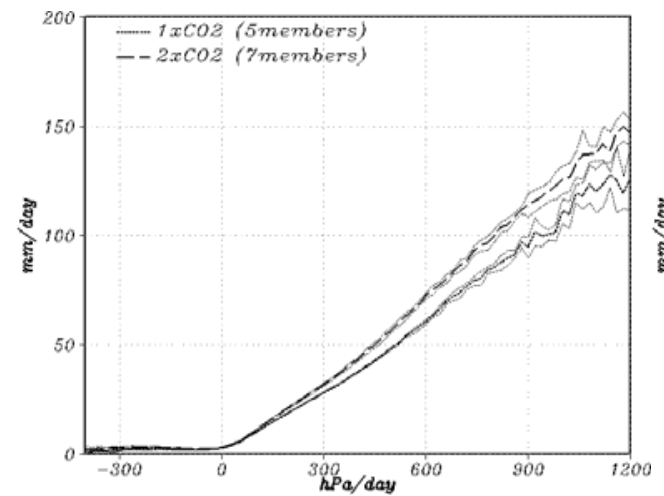

(a)

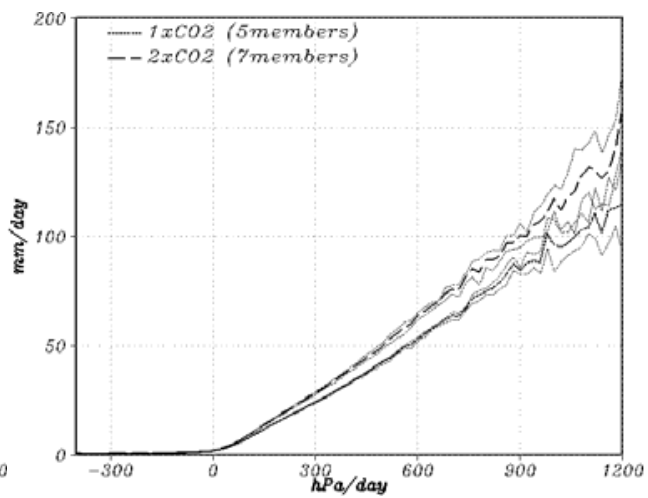

(b)

Fig. 3. As in Fig. 2, except for the expected daily precipitation intensity to daily $500 \mathrm{hPa}$ vertical velocity.

Figure 4 shows spatial distribution of dynamic and thermodynamic contribution for projected precipitation changes in South Asia $[25,26]$. Precipitation changes resulting from changes in dynamic circulation are dynamic change. Thermodynamic change (nondynamic) includes changes in precipitation features for given dynamic conditions and corresponds to intrinsic changes in precipitation mainly as a result of changes in atmospheric moisture content. Covariation is the change in these two effects. Covariation is not shown because the effect was negligible. Increased moisture convergence from enhanced atmospheric moisture is a thermodynamic effect. Increased moisture convergence from intensified convergence is a dynamic effect.

Figure 4 (a) and (b) shows dynamic and thermodynamic changes to mean precipitation change. Dynamic change reduces precipitation in a large portion of South Asia. Thermodynamic change generally enhances precipitation. Dynamic change, thermodynamic change, and covariance of mean precipitation change $(9.93 \%)$ over land $\left[8.5^{\circ}-30^{\circ} \mathrm{N}, 65^{\circ}-\right.$ $100^{\circ} \mathrm{E}$ ] were $0.30 \%, 9.64 \%$, and $-0.01 \%$. In regions including land and ocean, contributions of these components to mean precipitation change $(3.36 \%)$ were $-1.87 \%, 5.55 \%$, and $-0.32 \%$. Mean precipitation changes in global warming scenarios over land during the South Asian summer monsoon primarily arose from thermodynamic effects. Dynamic changes over land had only a small influence. Dynamic changes over regions including land and ocean that reduced the intensification of precipitation played a relatively large role. The dynamic component decreased (increased) daily precipitation due to decreased (increased) relatively strong (weak) upward motion due to the shifted mean (to ascent) and reduced variability in vertical motions (not shown). The mean spatial distribution of dynamic changes was related to reduced variability in vertical motions and was partly a result of an anticyclonic anomaly associated with a northward shift in circulation systems over the Arabian Sea and the Bay of Bengal (Fig. 1[c]). Thermodynamic changes, in contrast, increased daily precipitation in most dynamic regimes and were the primary factor enhancing precipitation. 
Figures 4 (c) and (d) indicate these contributions to extreme events -- the vertical velocity exceeds $500 \mathrm{hPa} /$ day; it approximately corresponds to the rainfall event of about 50 $\mathrm{mm} /$ day in South Asia $\left[8.5^{\circ}-30^{\circ} \mathrm{N}, 65^{\circ}-100^{\circ} \mathrm{E}\right]$ as in Figs. 2 and 3. The dynamic component in extreme events $(>500 \mathrm{hPa} /$ day $)$ contributed more to precipitation changes than the thermodynamic component in a large portion of the regions. Compared to thermodynamic change to total precipitation change (Fig. $4[\mathrm{~b}]$ ), thermodynamic change to extreme precipitation was the secondary factor in enhancing precipitation. On the southern edge of the Tibetan plateau, for instance, dynamic change rather than thermodynamic change contributes to precipitation.

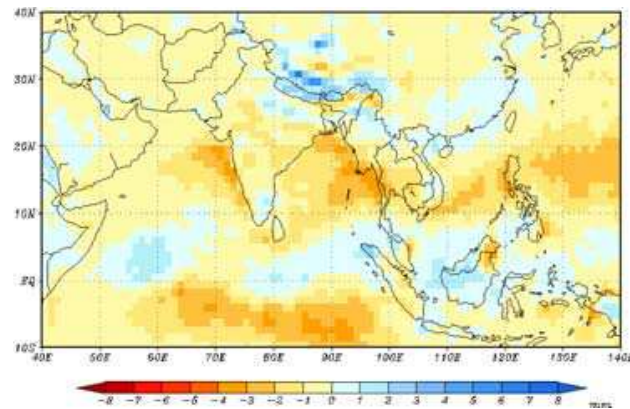

(a)

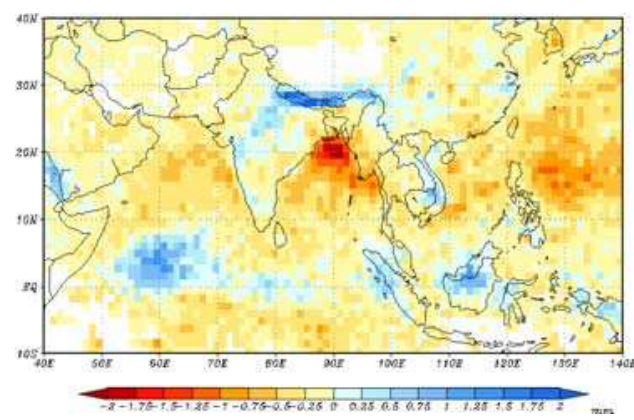

(c)

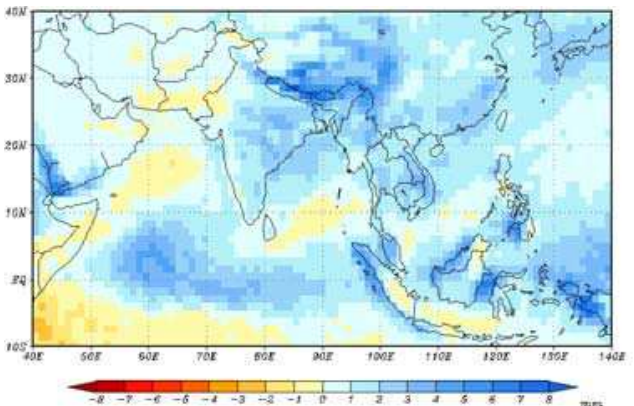

(b)

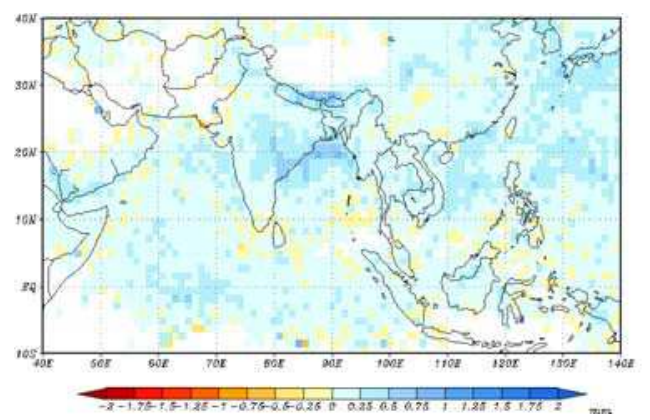

(d)

Fig. 4. Spatial distribution of dynamic and thermodynamic contribution (JJAS) to projected precipitation change. (a) Total dynamic component. (b) Total thermodynamic component.

(c) Dynamic component to extreme events -- vertical velocity exceeds $500 \mathrm{hPa} /$ day, (d) as in

(c), but for the thermodynamic component.

\subsection{Discussion}

Results of projected extreme events in the Asian summer monsoon with relatively highresolution ensemble simulation showed changes in the South Asian summer monsoon resulting from climate change. Model results under global warming conditions suggested more warming over land than over the ocean, a northward shift of lower tropospheric monsoon circulation, and an increase in mean precipitation during the Asian summer monsoon. The northward shift of circulation systems weakens large-scale monsoon indexes. 
This shift may arise from enhanced land-ocean thermal contrasts in South Asia and a modulation of Hadley-Walker circulation due to projected El Niño-like warming patterns in the tropical Pacific, although such a pattern is not present in all model projections.

The number of extreme daily precipitation events has increased significantly. Increases in mean and relatively strong precipitation were attributed to greater atmospheric moisture content -- a thermodynamic change. Changes in relatively strong precipitation resulting from climate change were consistent with increases in precipitable water. Although dynamic changes limited the intensification of mean precipitation, enhanced extreme precipitation over land in South Asia arose from dynamic rather than thermodynamic change.

Where moist convection predominated in the tropics, a net radiative cooling anomaly in the upper troposphere and a net radiative heating anomaly at the surface in response to increased $\mathrm{CO}_{2}$ increased upward latent heat transport. Resulting upper tropospheric warming increased the dry static stability (not shown), and enhanced stability suppressed the variability in vertical motions over most of the region investigated. The enhancement of extreme upward motion that occurred near mountainous areas, such as the southern edge of the Tibetan Plateau, regardless of changes in dry static stability, could be associated with a northward shift in monsoon circulation systems and could lead to more frequent extreme rainfall events on a regional basis -- a dynamic effect.

\section{Flood risk assessment in a watershed in Japan using multi-model ensemble projections based on 12 AOGCMs}

A key parameter in basin water management is local precipitation, and climate-change effects on heavy precipitation must be accurately estimated to prevent flood disasters. Relatively high-resolution GCMs are being developed and ensemble simulation by models are becoming available, but more frequently required basin-scale estimates to adapt to climate changes in the face of natural disaster are not sufficiently available to policy makers. Downscaling approaches can be used to produce finer scale information from GCMs with coarse spatial resolution via (i) statistical downscaling and (ii) dynamical downscaling [33, $34,35,36,37]$.

The sections that follow provide a case study of flood risk assessment in a watershed in Japan using multi-model ensemble projections based on 12 state-of-the-art AOGCMs provided by the IPCC-DDC [1] using statistical downscaling approach [38].

\subsection{Study area and analysis data}

The Tama River basin, an urbanized watershed near Tokyo, Japan, (139.76E, 35.69N) (Fig. 5), is $1240 \mathrm{~km}^{2}$ in area for a main stream $138 \mathrm{~km}$ long. The basic and estimated high-water discharges are 8700 and $6500 \mathrm{~m}^{3} / \mathrm{s}$, determined using 2-day precipitation with a 200-year return period.

We studied changes in the 200-year quantile in Tokyo caused by global warming using results from the 12 GCMs based on simulated precipitation data in 1981-2000 (2000), 20462065 (2050), 2081-2100 (2100), 2181-2200 (2200), and 2281-2300 (2300) under SRES A1B and B1 scenario conditions.

Table 1 lists GCMs and their simulated precipitation in 2000. Annual average precipitation, 2-day maximum precipitation, 40th largest 2-day precipitation, and extreme precipitation 
were calculated and compared to observed data. Regrettably, model bias is relatively large and no model can agree well with observation.

Heavy precipitation was defined as that in a partial duration series (PDS) [39] composed of 40 largest 2-day precipitations for 20 years.

In other words, the PDS was the time series exceeding the threshold which was set to the 40th largest 2-day precipitation. The frequency distribution for precipitation in the PDS is

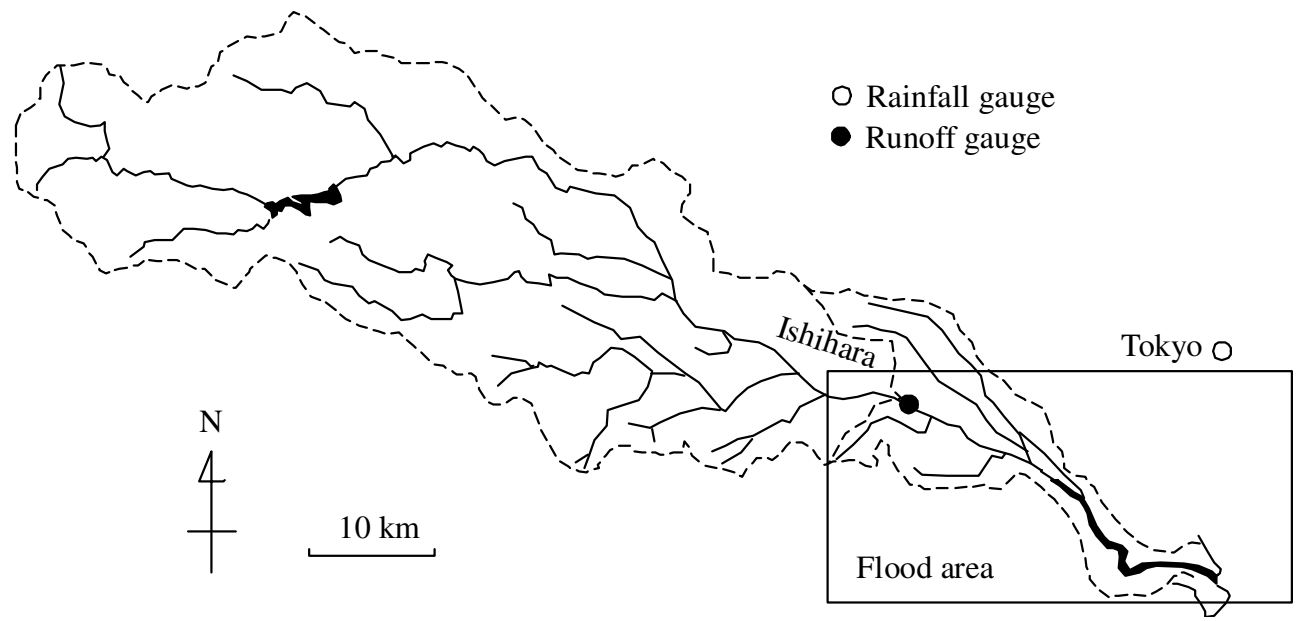

Fig. 5. Tama River basin overview.

\begin{tabular}{|c|c|c|c|c|c|c|c|c|}
\hline \multirow[b]{2}{*}{ Model } & \multirow[b]{2}{*}{ IPCC ID } & \multirow{2}{*}{\multicolumn{2}{|c|}{$\begin{array}{l}\text { Resolution } \\
\text { long. } \times \text { lat. } \\
\text { (degree) }\end{array}$}} & \multicolumn{3}{|c|}{ Precipitation (1981-2000) } & \multicolumn{2}{|c|}{ Quantile (1981-2000) } \\
\hline & & & & $\begin{array}{l}\text { Annual } \\
\text { Average } \\
\text { (mm/year) }\end{array}$ & $\begin{array}{c}\text { 2-day } \\
\text { Maximum } \\
\text { (mm/2-day) }\end{array}$ & $\begin{array}{c}\text { 2-day } \\
\text { 40th } \\
\text { (mm/2-day) }\end{array}$ & $\begin{array}{l}\text { 100-year } \\
\text { (mm/2-day) }\end{array}$ & $\begin{array}{l}\text { 200-year } \\
\text { (mm/2-day) }\end{array}$ \\
\hline Observed (Tokyo) & & & & 1479 & 294 & 86 & 376 & 415 \\
\hline Model emsemble & & & & 1733 & 151 & 66 & 170 & 184 \\
\hline cccma_cgcm3_1 & CGCM3.1(T47) & 3.8 & 3.7 & 1834 & 170 & 71 & 216 & 236 \\
\hline cnrm_cm3 & CNRM-CM3 & 2.8 & 2.8 & 2227 & 214 & 86 & 266 & 290 \\
\hline csiro_mk3_0 & CSIRO-Mk3.0 & 1.9 & 1.9 & 1600 & 124 & 61 & 139 & 149 \\
\hline gfdl_cm2_0 & GFDL-CM2.0 & 2.5 & 2.0 & 1671 & 175 & 66 & 201 & 219 \\
\hline giss_aom & GISS-AOM & 4.0 & 3.0 & 1795 & 68 & 49 & 89 & 94 \\
\hline giss_model_e_r & GISS-ER & 5.0 & 4.0 & 1065 & 66 & 41 & 72 & 76 \\
\hline iap_fgoals1_0_g & FGOALS-g1.0 & 2.8 & 2.8 & 2077 & 144 & 77 & 162 & 173 \\
\hline ipsl_cm4 & IPSL-CM4 & 3.8 & 2.5 & 2106 & 363 & 104 & 344 & 376 \\
\hline miroc3_2_hires & MIROC3.2(hires) & 1.1 & 1.1 & 1823 & 143 & 70 & 147 & 157 \\
\hline miroc3_2_medres & MIROC3.2(medres) & 2.8 & 2.8 & 1863 & 108 & 63 & 128 & 136 \\
\hline miub_echo_g & ECHO-G & 3.8 & 3.7 & 1138 & 110 & 46 & 130 & 141 \\
\hline ncar_pcm 1 & PCM & 2.8 & 2.8 & 1601 & 123 & 57 & 145 & 157 \\
\hline
\end{tabular}

Table 1. GCMs with resolutions and simulated precipitation in present climate. 
set as dimensionless using maximum $\left(x_{\max }\right)$ and threshold precipitation $\left(x_{0}\right)$ in each model (Figure 6). The ensemble average of dimensionless precipitation frequency in 2000 agrees with that observed, and its probability density function is approximated by an exponential distribution. We also clarified that the frequency distribution does not change in 2050, 2100, 2200 , or 2300 .

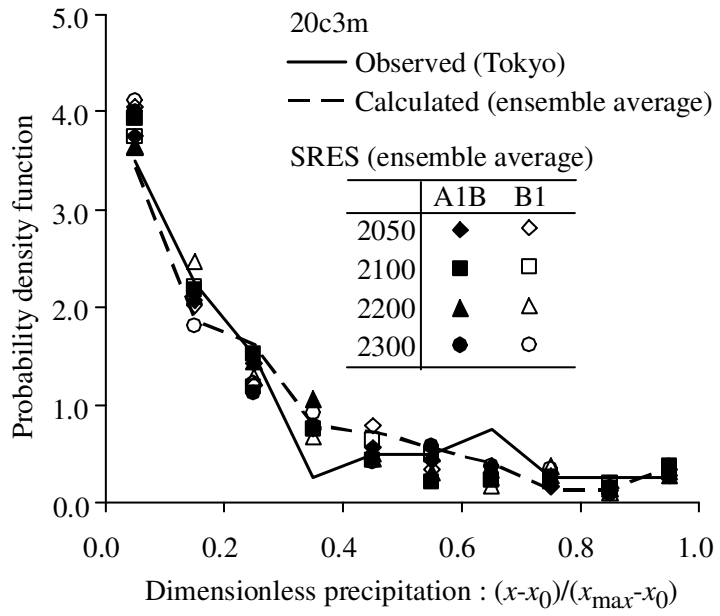

Fig. 6. Frequency distribution of precipitation in the PDS.

\subsection{Changes in 200-year quantile caused by global warming}

Figures 7 show changes in average precipitation in PDS caused by global warming. The values in 2000 are set to 1 in each model, and the ratio is used to calculate the ensemble average. The ensemble average ratio of change to the present one is $1.09-1.20$ in the A1B scenario and 1.03-1.07 in the B1 scenario. Almost all model output in the A1B scenario indicates that future precipitation will exceed that in the present (Fig. 7(a)). Some model output indicates a trend toward a slight decrease in the B1 scenario (Fig. 7(b)).

In changes in the projected 200-year quantile caused by global warming (Figures 8), the ratio of the ensemble average of this quantile to the present one is 1.07-1.20 in the A1B scenario, indicating that heavy precipitation will slightly increase but not a statistically significant trend. The ratio remains stable at 1.0 in the B1 scenario, however, possibly because of less enhanced atmospheric moisture content associated with greenhouse gas concentration lower than that in the A1B scenario.

\subsection{Global warming impact on flood risk}

To assess changes in the estimated high-water discharge in the Tama River basin in the A1B scenario, we conducted rainfall runoff analyses under present geophysical conditions using the kinematic runoff model and unit hydrograph method to calculate direct discharge and base flow at Ishihara (Fig. 5) [38].

The kinematic runoff model [40] considers topography, land cover, channel networks, and storage facilities. The basin was divided into subbasins, each of which was modeled using two slopes and a channel. Slope and channel flows are approximated by a kinematic wave. Effective rainfall was calculated using a cumulated-retained curve. Flood risk was evaluated 


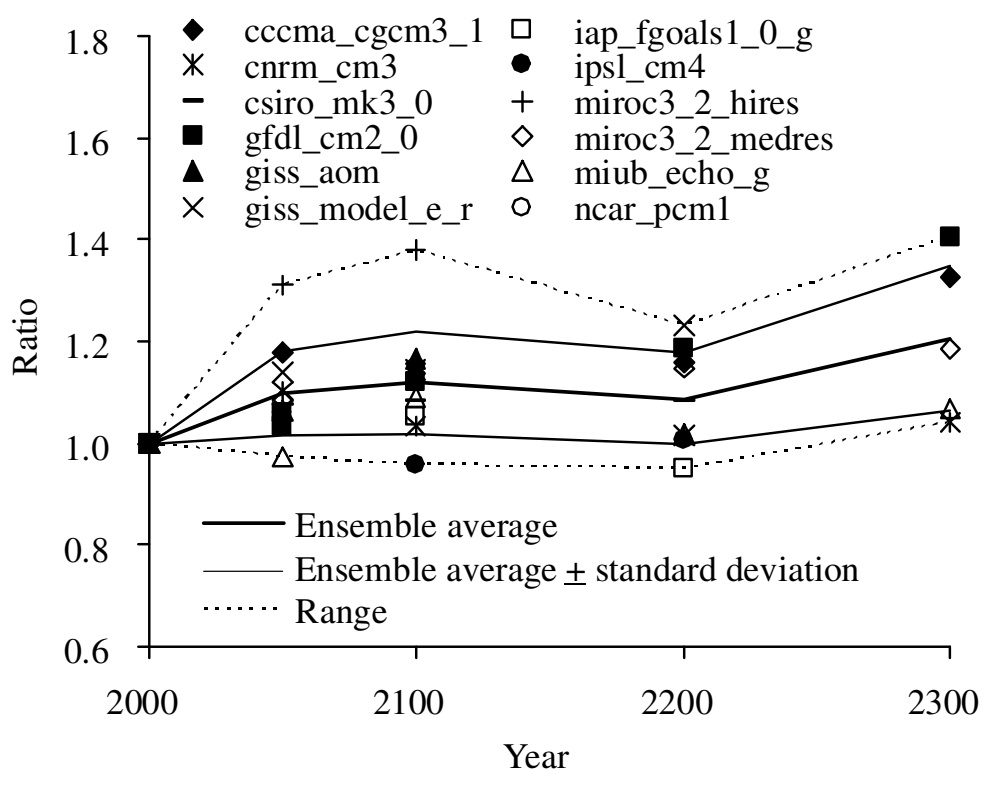

(a) A1B

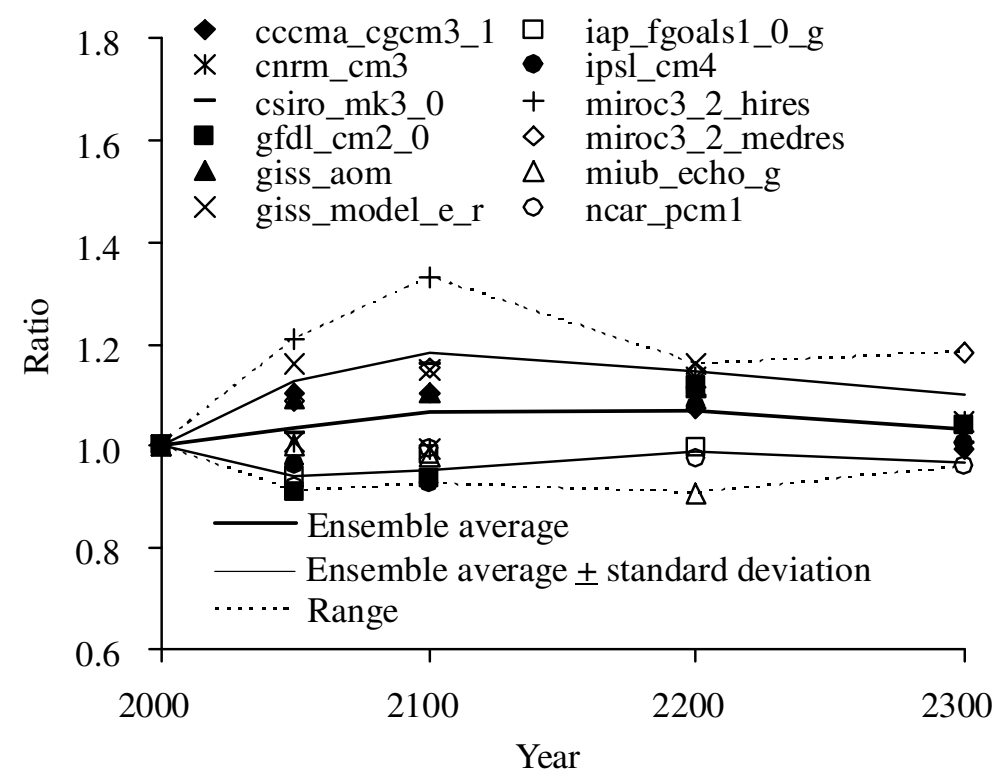

(b) B1

Fig. 7. Changes in average precipitation in the PDS caused by global warming. 


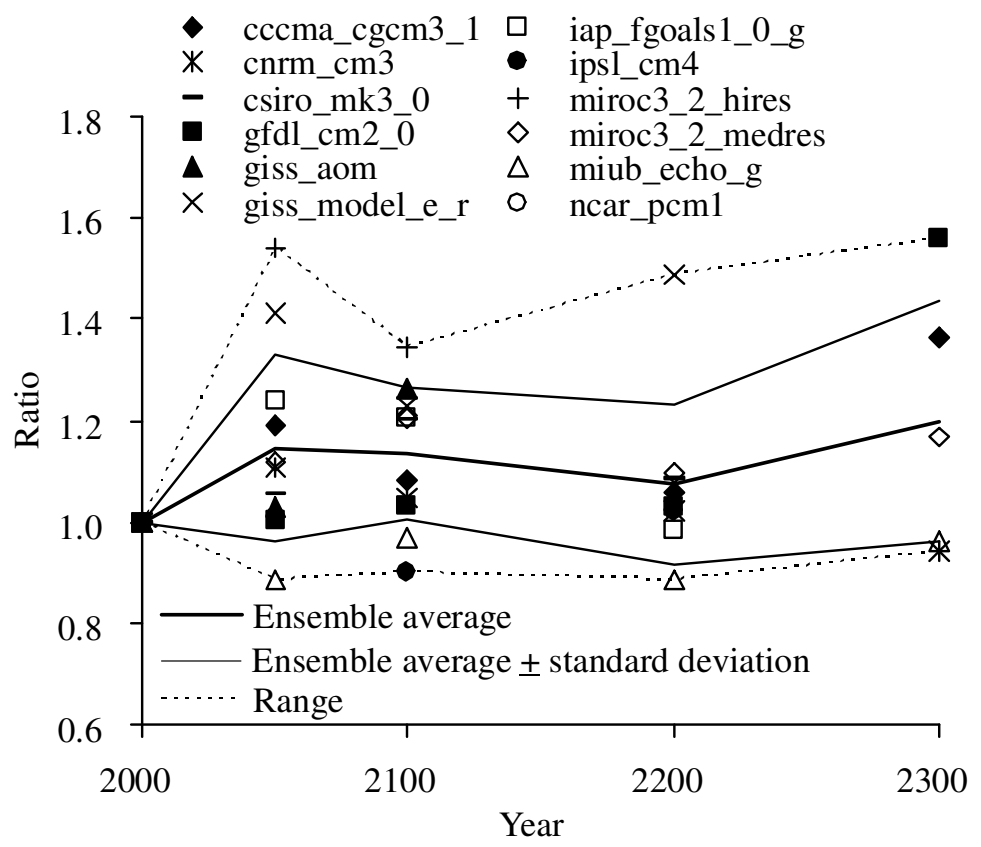

(a) A1B

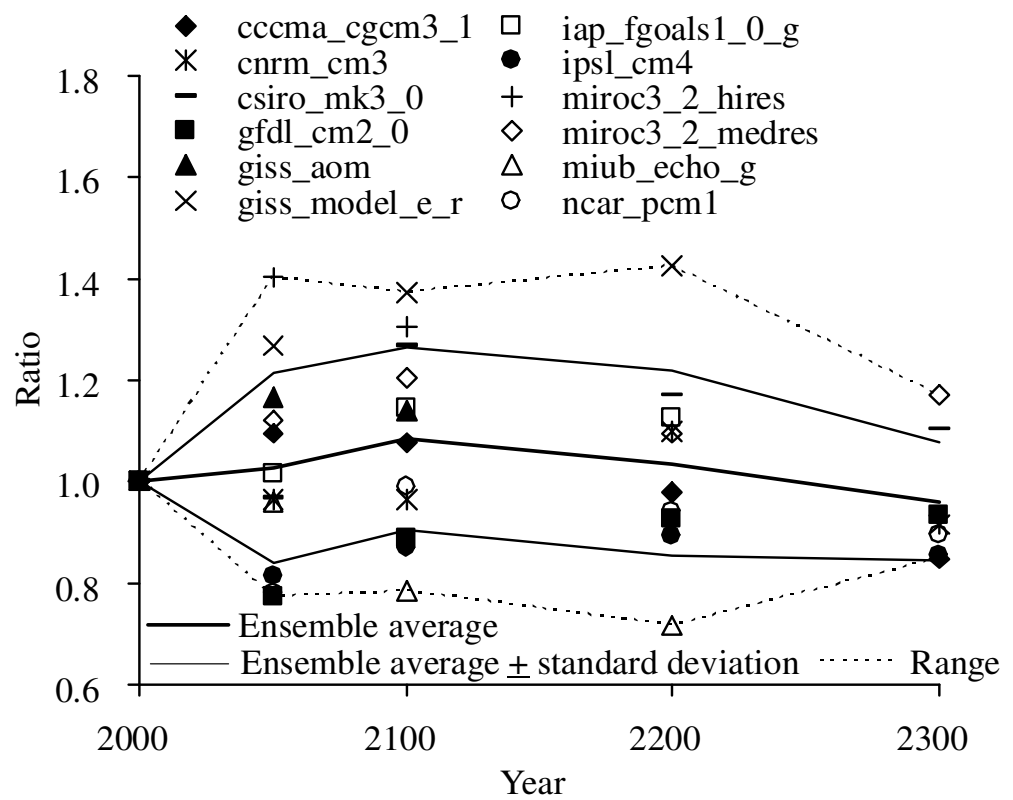

(b) B1

Fig. 8 . Changes in the 200-year quantile caused by global warming. 
using numerical simulation for precipitation with a 200-year return period. The downstream area at Ishihara was defined as the inundation flow analysis area (Fig. 5). Tama River flow was analyzed one-dimensionally applying St. Venant equations, and flood plain inundation was analyzed two-dimensionally. Flows in the river and flood plain were combined using a weir discharge formula [41].

The 200-year quantiles in 2000 (present), 2050, 2100, 2200, and 2300 were set at 457, 523, 519, 491, and $548 \mathrm{~mm} / 2$-day based on the ensemble average in Fig. 8(a). The 200-year quantile in 2000 (present) corresponds to the 63, 72, 106, and 58-year quantiles in 2050, 2100, 2200, and 2300. Although extreme precipitation varies quite greatly due to large multi-decadal natural variability and the nonlinear response of hydrological cycles to global warming, we concluded that the 200-year quantile extreme event in the present climate is projected to occur in much shorter return periods in the A1B scenario.

Hyetograph (Figure 9) was defined as observed hourly precipitation from 10:00 on August 30 to 10:00 on September 1, 1949 -- one of the largest 2-day precipitations -- and multiplied by a constant so that 2-day precipitation equals the 200-year quantile in each period. Simulated changes in high water discharge and flood volume in the A1B scenario show ratios of the estimated high-water discharge to the present one to be 1.10-1.26 and those of the flood volume to be 1.46-2.31 (Figure 9). Flood volume increases dramatically compared to the increase in precipitation (Figure 10).

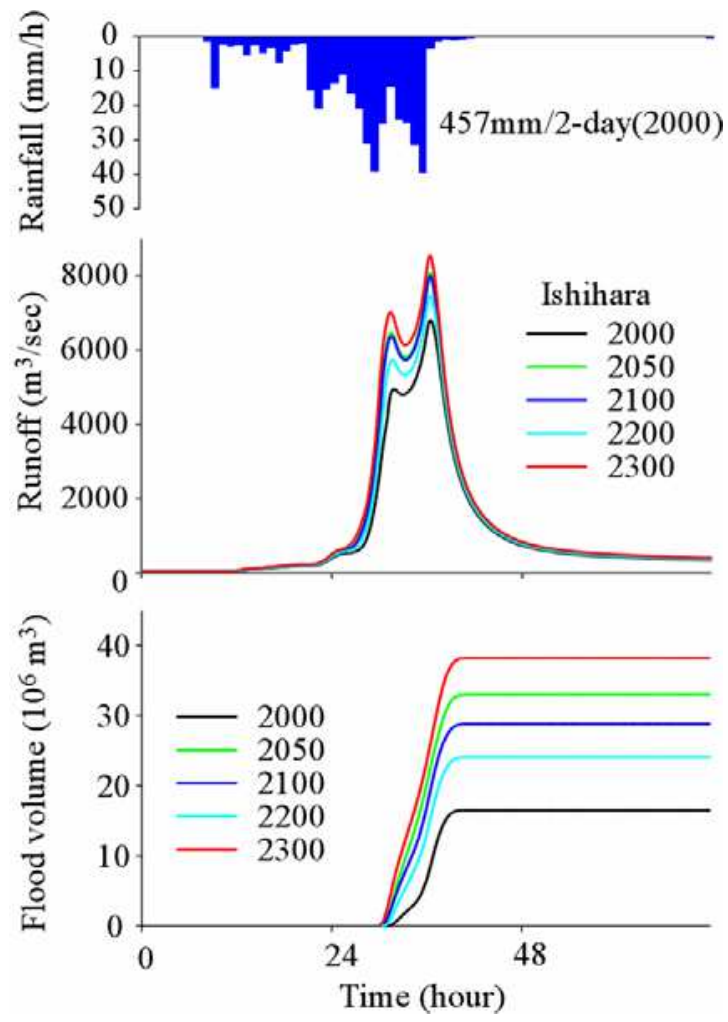

Fig. 9. Changes in hydrograph and flood volume in the A1B scenario. 


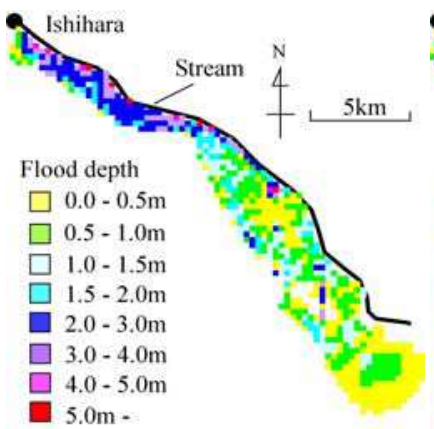

2000

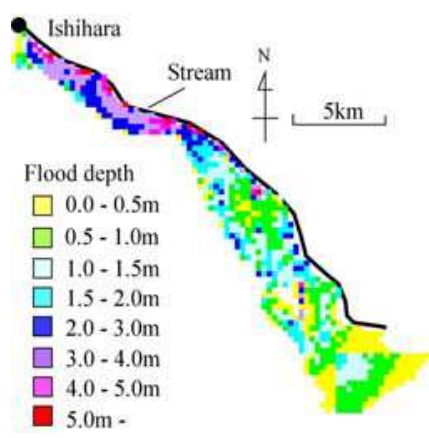

2200

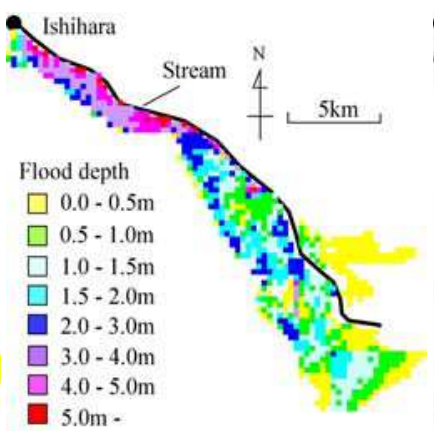

2050

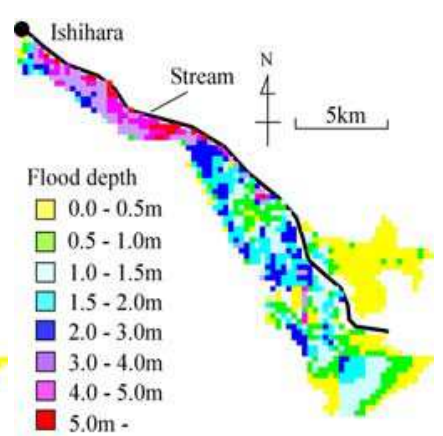

2300

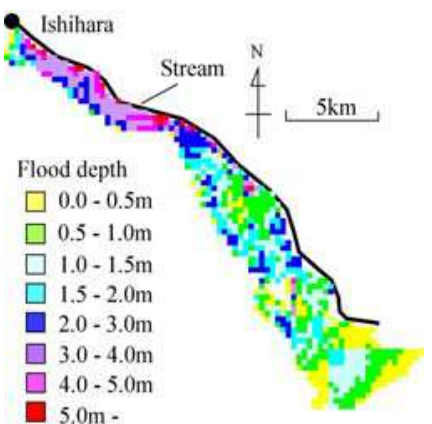

2100

Fig. 10. Distribution of flood depth.

We used the multi-model ensemble average as a scenario of heavy precipitation for assessing the impact of climate change on risk of flood inundation. Even though heavy precipitation is slightly increased, the simulated results indicate the risk of flood in the basin is much higher than the present one in the A1B global warming scenario.

\section{Summary}

Two recent attempts at hydrologic projection in Asia were addressed. Time-slice ensemble experiments using a high-resolution (T106) AGCM on the earth simulator indicated changes in the South Asian summer monsoon resulting from climate change. Model results under global warming conditions suggested more warming over land than over the ocean, a northward shift of lower tropospheric monsoon circulation, and an increase in mean precipitation during the Asian summer monsoon. The number of extreme daily precipitation events increased significantly. Increases in mean and extreme precipitation were attributed to greater atmospheric moisture content -- a thermodynamic change. In contrast, dynamic changes limited the intensification of mean precipitation. Enhanced extreme precipitation over land in South Asia arose from dynamic rather than thermodynamic changes.

Results above obtained from high-resolution time-slice ensemble simulation are fairly robust. Ocean-atmosphere coupling is a basic feature of the Asian summer monsoon, and 
significant discrepancies exist between forced and coupled experiments [42, 43, 44]. Because dynamical downscaling by a regional climate model depends strongly on the results of parent GCMs, the robustness of results in the present study must be assessed using ensemble experiments based on high-resolution AOGCMs or AGCMs that are coupled to a slab ocean model.

Section 3 describes the impact of global warming on heavy precipitation features and flood risk, using 2-day precipitation of 12 AOGCMs. PDS-based frequency analysis indicated that multi-model ensemble average 200-year quantiles in Tokyo from 2050 to 2300 under IPCC SRES-A1B scenario climate conditions were 1.07-1.20 times as large as that under present climate conditions. The 200-year quantile extreme events in the present are projected to occur in much shorter return periods in the A1B scenario. Studying these influences on runoff discharge and flood risk in the Tama River basin using numerical simulation, we found that high-water discharge is projected to rise by $10 \%-26 \%$ and flood volume increase by $46 \%-131 \%$ in precipitation with a 200 -year return period. Even though the increase of extreme precipitation as a result of global warming is not substantial, the risk of flooding in the basin is thus projected to be much higher than the present.

Climate-related disasters are serious problems in Asia. Advances in the understanding of meteorology and in the development of monitoring and forecasting systems have enhanced early warning systems, contributing immensely to reducing fatalities resulting from typhoons, cyclones, and floods. The frequency of extreme events causing water-related disasters has, however, been increasing in the last decade and may be increased in the future due to anthropogenic activity. The most advanced and trustworthy regional risk assessment for climate change is an urgent issue, and relatively high-resolution global climate models are not yet capabile of determining regional-scale feedback, especially between atmosphere and complex heterogeneous land surfaces such as topography and terrestrial ecosystems. Spatial resolution of less than $30 \mathrm{~km}$ grid spacing must thus be added and multi-model ensembles by RCMs and GCMs be conducted that include biophysical and biogeochemical processes to accurately assess critical interactions within systems.

\section{Acknowledgments}

The first part of the work was supported in part by the Global Environment Research Fund of Japan's Ministry of the Environment. Model simulations were made by the Earth Simulator at the Japan Agency for Marine-Earth Science and Technology for the Category 1 Research Revolution 2002 (RR2002) project of MEXT. We thank K-1 Japan project members for their support and feedback. The second part of this work was conducted as one of the research activities of the research project "Study on future changes in the global hydrologic cycle related disasters" of National Research Institute for Earth Science and Disaster Prevention. This research was partially supported by the resarch project on the disaster risk information platform by national research institute for earth science and disaster prevention, Japan. We also acknowledge the international modeling groups for providing their data for analysis, the PCMDI for collecting and archiving the model data.

\section{References}

[1] IPCC, Climate Change 2007: The physical science basis. Summary for policymakers, contribution of working group I to the fourth assessment report of the Intergovernmental Panel on Climate Change, 2007. 
[2] Schnur, R., 2002, The investment forecast. Nature, 415, 483-484.

[3] Palmer, T.N., and Rälsänen, J., 2002, Quantifying the risk of extreme seasonal precipitation events in a changing climate. Nature, 415, 512-514.

[4] Trenberth, K.E., Dai A., Rasmussen, R.M., and Parsons, D.B., 2003, The changing character of precipitation. Bulletin of the American Meteorological Society, 84, 12051217.

[5] Held, I.M., and Soden B.J., 2006, Robust responses of the hydrological cycle to global warming. Journal of climate, 19, 5686-5699.

[6] Soden, B.J., Jackson, D.L., Ramaswamy, V., Schwarzkopf, M.D., Huang, X., 2005, The radiative signature of upper tropospheric moistening. Science, 310, 841-844.

[7] Emanuel, K., 2005, Increasing destructiveness of tropical cyclones over the past 30 years. Nature, 436, 686-688.

[8] Webster, P.J., Holland, G.J., Curry, J.A., and Chang, H.-R., 2005, Changes in topical cyclone number, duration, and intensity in a warming environment. Science, 309, 1844-1846.

[9] Hasegawa, A., and Emori, S., 2005, Tropical cyclones and associated precipitation over the Western North Pacific: T106 atmospheric GCM simulation for present-day and doubled CO2 climates, Scientific Online Letters on the Atmosphere, 1, 145-148.

[10] Oouchi, K., Yoshimura, J., Yoshimura, H., Mizuta, R., Kusunoki, S., and Noda, A., 2006, Tropical cyclone climatology in a global-warming climate as simulated in a $20 \mathrm{~km}$ mesh global atmospheric model: Frequency and wind intensity analyses. Journal of the Meteorological Society of Japan, 84(2), 259-276.

[11] Coe, M.T., 2000, Modeling terrestrial hydrological systems at the continental scale: testing the accuracy of an atmospheric GCM. Journal of Climate, 13, 686-704.

[12] Koster, R.D., Suarez, M.J., and Heiser, M., 2000, Variance and predictability of precipitation at seasonal-to-interannual timescales. Journal of Hydrometeorology, 1, 26-46.

[13] Vörösmarty, C.J., Green, P., Salisbury, J., and Lammers, R.B., 2000, Global water resources: vulnerability from climate change and population growth. Science, 289, 284-288.

[14] Milly, P.C.D., Wetherald, R.T., Dunne, K.A., and Delworth, T.L., 2002, Increasing risk of great foods in a changing climate. Nature, 415, 514-517.

[15] Meehl, G.A., and Washington, W.M., 1993, South Asian summer monsoon variability in a model with doubled atmospheric carbon dioxide concentration. Science, 260, 11011104.

[16] Meehl, G.A., and Arblaster, J.M., 2003, Mechanisms for projected future changes in South Asian monsoon precipitation. Climate Dynamics, 21, 659-675.

[17] Bhaskaran, B., Mitchell, J.F.B., Lavery, J.R., and Lal, M., 1995, Climatic response of the Indian subcontinent to doubled $\mathrm{CO} 2$ concentrations. International Journal of Climatology, 15, 873-892.

[18] Kitoh, A., Yukimoto, S., Noda, A., and Motoi, T., 1997, Simulated changes in the Asian summer monsoon at times of increased atmospheric $\mathrm{CO} 2$. Journal of the Meteorological Society of Japan, 75, 1019-1031.

[19] Hu, Z.-Z., Latif, M., Roeckner, E., and Bengtsson, L., 2000, Intensified Asian summer monsoon and its variability in a coupled model forced by increasing greenhouse gas concentrations. Geophysical Research Letters, 27, 2681-2684. 
[20] Ashrit, R.G., Douville, H., and Rupa Kumar, K., 2003, Response of the Indian monsoon and ENSO-monsoon teleconnection to enhanced greenhouse effect in the CNRM coupled model. Journal of the Meteorological Society of Japan, 81, 779-803.

[21] Douville, H., Royer, J.-F., Polcher, J., Cox, P.M., Gedeney, N., Stephenson, D.B., and Valdes, P.J., 2000, Impact of CO2 doubling on the Asian summer monsoon: Robust versus model-dependent responses. Journal of the Meteorological Society of Japan, 78, 421-439.

[22] May, W., 2004, Potential future changes in the Indian summer monsoon due to greenhouse warming: analysis of mechanisms in a global time-slice experiment. Climate Dynamics, 22, 389-414.

[23] Mitchell, J.F.B., and Johns, T.C., 1997, On modification of global warming by sulfate aerosols. Journal of Climate, 10, 245-267.

[24] May, W., 2004, Simulation of the variability and extremes of daily rainfall during the Indian summer monsoon for present and future times in a global time-slice experiment. Climate Dynamics, 22, 183-204.

[25] Emori, S., and Brown, S.J., 2005, Dynamic and thermodynamic changes in mean and extreme precipitation under changed climate. Geophysical Research Letters, 32, L17706.

[26] Dairaku, K., and Emori, S., 2006, Dynamic and thermodynamic influences on intensified daily rainfall during the Asian summer monsoon under doubled atmospheric $\mathrm{CO} 2$ conditions. Geophysical Research Letters, 33, L01704.

[27] Numaguti A., Takahashi M., Nakajima T., and Sumi A., 1997, Description of CCSR/NIES atmospheric general circulation model. CGER's Supercomputer Monograph Report. 3, pp 1-48. Center for Global Environmental Research, National Institute for Environmental Studies.

[28] Emori, S., Hasegawa, A., Suzuki, T., and Dairaku, K., 2005, Validation, parameterization dependence and future projection of daily precipitation simulated with a highresolution atmospheric GCM. Geophysical Research Letters, 32, L06708.

[29] Rayner, N.A., Parker, D.E., Horton, E.B., Folland, C.K., Alexander, L.V., Rowell, D.P., Kent, E.C., and Kaplan, A., 2003, Global analyses of sea surface temperature, sea ice, and night marine air temperature since the late nineteenth century. Journal of Geophysical Research, 108, 4407.

[30] Sontakke, N.A., Plant, G.B., and Singh, N., 1993, Construction of all India rainfall series for the period 1844-1991. Journal of Climate, 6, 1807-1811.

[31] Webster, P.J., and YANG, S., 1992, Monsoon and ENSO: Selectively interactive systems. The Quarterly Journal of the Royal Meteorological Society, 118, 877-926.

[32] Goswami, B.N., Krishnamurthy, V., and Annamalai, H., 1999, A broad scale circulation index for interannual variability of the Indian summer monsoon. The Quarterly Journal of the Royal Meteorological Society, 125, 611-633.

[33] Dairaku, K., Emori, S., and Nozawa, T., 2005, Hydrological projection under the global warming in Asia with a regional climate model nested in a general circulation model. Annual Journal of Hydraulic Engineering, JSCE, 49(1), 397-402. (in Japanese with an English Summary)

[34] Dairaku, K., Emori, S., 2007, Potential hydrological change resulting from greenhouse warming: Climate change and water-related disasters of severe tropical storms in 
East Asia, Research Signpost "Geophysics", Tomonori Matsuura, Ryuichi Kawamura Eds., pp.105-123.

[35] Koji Dairaku, Seita Emori, Toru Nozawa(2008): Impacts of Global Warming on Hydrological Cycles in the Asian Monsoon Region, Advances in Atmospheric Sciences, 25, No. 6, pp.960-973

[36] Koji Dairaku, Seita Emori, Hironori Higashi(2008): Potential changes in extreme events under global climate change, Journal of Disaster Research, 3, No. 1, pp.39-50

[37] Castro, C.L., Pielke Sr, R.A., and Leoncini, G., 2005, Dynamical downscaling: Assessment of value retained and added using the Regional Atmospheric Modeling System (RAMS). Journal of Geophysical Research, 110, D05108.

[38] Higashi, H., 2007, Influences of climate change on the frequencies of storm rainfalls and flood disasters, Research Signpost "Geophysics", Tomonori Matsuura, Ryuichi Kawamura Eds., pp.125-143.

[39] Stedinger, J.R., Vogel, R.M., and Foufoula-Georgiou, E., 1993, Frequency analysis of extreme events, Handbook of Hydrology, Maindment, D.J., ed. McGraw-Hill, ch. 18, 166.

[40] Iwagaki, Y., 1955, Fundamental studies on the runoff analysis by characteristics. Bulletin of the Disaster Prevention Research Institute, Kyoto University, 5(10), 1-25.

[41] Inoue, K., Toda, K., and Maeda, O., 2000, Inundation model in the region of river network system and its application to Mekong delta. Annual Journal of Hydraulic Engineering, JSCE, 44, 485-490.

[42] Douville, H., 2005, Limitations of time-slice experiments for predicting regional climate change over South Asia. Climate Dynamics, 24, 373-391.

[43] Inatsu, M., and Kimoto, M., 2005, Difference of boreal summer climate between coupled and atmosphere-only GCMs. Scientific Online Letters on the Atmosphere, 1, 105-108.

[44] Hasegawa A., Emori, S., 2007, Effect of air-sea coupling in the assessment of $\mathrm{CO}_{2-}$ induced intensification of tropical cyclone activity, Geophysical Research Letters, 34, L05701. 


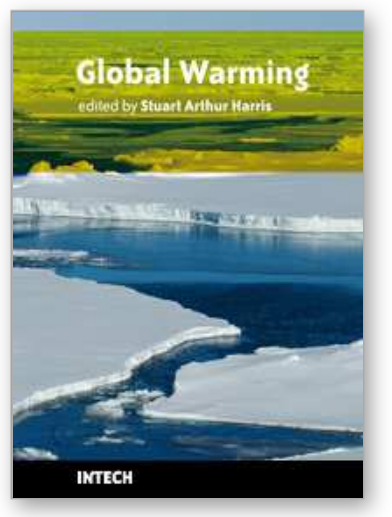

\author{
Global Warming \\ Edited by Stuart Arthur Harris
}

ISBN 978-953-307-149-7

Hard cover, 250 pages

Publisher Sciyo

Published online 27, September, 2010

Published in print edition September, 2010

This book is intended to introduce the reader to examples of the range of practical problems posed by "Global Warming". It includes 11 chapters split into 5 sections. Section 1 outlines the recent changes in the Indian Monsoon, the importance of greenhouse gases to life, and the relative importance of changes in solar radiation in causing the changes. Section 2 discusses the changes to natural hazards such as floods, retreating glaciers and potential sea level changes. Section 3 examines planning cities and transportation systems in the light of the changes, while section 4 looks at alternative energy sources. Section 5 estimates the changes to the carbon pool in the alpine meadows of the Qinghai-Tibet Plateau. The 11 authors come from 9 different countries, so the examples are taken from a truly international set of problems.

\title{
How to reference
}

In order to correctly reference this scholarly work, feel free to copy and paste the following:

Koji Dairaku (2010). Potential Changes in Hydrologic Hazards Under Global Climate Change, Global Warming, Stuart Arthur Harris (Ed.), ISBN: 978-953-307-149-7, InTech, Available from: http://www.intechopen.com/books/global-warming/potential-changes-in-hydrologic-hazards-under-globalclimate-change

\section{INTECH}

open science | open minds

\section{InTech Europe}

University Campus STeP Ri Slavka Krautzeka 83/A 51000 Rijeka, Croatia Phone: +385 (51) 770447 Fax: +385 (51) 686166 www.intechopen.com

\author{
InTech China \\ Unit 405, Office Block, Hotel Equatorial Shanghai \\ No.65, Yan An Road (West), Shanghai, 200040, China \\ 中国上海市延安西路65号上海国际贵都大饭店办公楼405单元 \\ Phone: +86-21-62489820 \\ Fax: +86-21-62489821
}


(C) 2010 The Author(s). Licensee IntechOpen. This chapter is distributed under the terms of the Creative Commons Attribution-NonCommercialShareAlike-3.0 License, which permits use, distribution and reproduction for non-commercial purposes, provided the original is properly cited and derivative works building on this content are distributed under the same license. 